\title{
Analysis of Changing Factors on Airborne Allergenic Pollens Distribution in Taiyuan Downtown, North China
}

\author{
Kejun Zhang, Binquan Wang*, Yanli Zhang, Nasha Cheng, Changsheng Wang, \\ Chunming Zhang, Wei Gao, Ganggang Chen \\ Department of Otolaryngology, Head and Neck Surgery, First Hospital, Shanxi Medical University, Taiyuan, \\ China \\ Email: zhangkejun54@126.com, ${ }^{*}$ wbq xy@sxent.org
}

Received 28 February 2015; accepted 15 March 2015; published 19 March 2015

Copyright (C) 2015 by authors and Scientific Research Publishing Inc.

This work is licensed under the Creative Commons Attribution International License (CC BY). http://creativecommons.org/licenses/by/4.0/

(c) (i) Open Access

\section{Abstract}

To study and analyse 2 surveys on airborne allergenic pollens distribution in Taiyuan Downtown, North China 30 years apart, the surveys focused on the phenomenon and the influence factors on types, counts, drift patterns, growth and decline rhythm and distribution features of airborne pollen with the same methods in the region in March 1977 to February 1978 and July 2008 to June 2009 , respectively. The data of two airborne pollens surveys were treated with statistics, comparation and analysis, and the influence factors of pollen distribution in Taiyuan Downtown were explored. In the 2 surveys, 24 species and 35 species of pollen were collected in the region, respectively. Two pollen drift peaks were formed in spring and autumn in the two surveys. Artemisia $L$. is still the absolute dominant allergy airborne pollen. The types, counts, drift patterns and composition of pollen in air could be changed by the plants variation. Climate warming might affect pollen peak appearing time and lasting time, climate warming and Poplar \& Willow contents changes in spring and autumn reversed the airborne pollen peak. It was found that Humulus L. had become the region's main allergic pollen. Invasive strong allergen ragweed was spread to the inland city Taiyuan. Allergists should focus on exotic invasive harmful plants in the region.

\section{Keywords}

Airborne Pollen, Identification of Pollen, Pollen Count, Seasonal Distribution of Airborne Pollen, Taiyuan

\footnotetext{
${ }^{*}$ Corresponding author.
}

How to cite this paper: Zhang, K.J., Wang, B.Q., Zhang, Y.L., Cheng, N.S., Wang, C.S., Zhang, C.M., Gao, W. and Chen, G.G. (2015) Analysis of Changing Factors on Airborne Allergenic Pollens Distribution in Taiyuan Downtown, North China. International Journal of Otolaryngology and Head \& Neck Surgery, 4, 148-155. http://dx.doi.org/10.4236/ijohns.2015.42026 


\section{Introduction}

Hay fever caused by airborn pollens is worldwide common and frequently-occurring diseases, and belongs to the environmental diseases. Strictly speaking, there is the existence of patients suffering from hay fever wherever there are higher plants. More than 50 million people worldwide suffer from hay fever [1]. It was reported in 2005 that by more than 5000 samples of epidemiological survey, it was found that the incidence of hay fever and mild nasal allergy in survey area in China was as much as 17.8\% [2]. It was reported in 2007 that 38203 persons in 11 cities in China were interviewed by telephone and the incidence of allergic rhinitis ranged between 8.7\% - 24.1\% in different cities [3]. An airborne pollen survey was conducted for a period of a year in 1970s in Taiyuan Downtown, North China [4] [5], so far in the past 30 years. With the process of urbanization in Taiyuan, urban strengthening virescence, vegetation variation and exotic invasive harmful plants, the airborne pollen types and counts may change. China is a vast territory country and different regions have different pollen distributions. There were at least 5 - 10 million pollen allergic patients in China and in recent years the incidence of pollinosis rate had a growth trend [1]. To re-survey the distribution of pollen and its influencing factors in the region will have an important significance on allergenic pollen prevention and treatment in North China. For this purpose, an airborne pollen re-survey and study was conducted with the same methods in the region in July 1, 2008 to June 30, 2009, and the re-survey result was compared with survey result in the same region in March 1977 to February 1978 [6]. It is believed that two pollen surveys 30 years apart in the same place should be the first in China. After the influencing factors on the two survey results on airborne pollen distribution in this region were analyzed and researched, the research findings would be reported as follows.

\section{Materials and Methods}

\subsection{Preparation of Pollen Standard Slides}

The 28 pollen standard slides were prepared according to the preparing method [7] developed by Beijing Union Medical College Hospital and used for identification of airborne pollens in the survey. The pollens were collected locally or provided by Allergy Department of Beijing Union Medical College Hospital.

\subsection{Collection of Airborne Pollens}

Ye’s [1]-[8] airborne pollen fixed-point sampler was made with gravity sedimentation method according to national uniform standard [7]. The petrolatum alba and glycerol agar-basic fuchsin stain [7] were prepared and placed in the refrigerator for spare. The pollen sampler was placed on the roof of the 4 storey outpatient building of First Hospital of Shanxi Medical University and was maintained in the location basically the same as 30 years ago with a height $(12 \mathrm{~m})$ [5] and coordinate (longitude $112^{\circ} 30^{\prime}$ [5], latitude $37^{\circ} 52^{\prime}$ [5]). One slide was exposed daily to collect airborne pollens.

\subsection{Counting and Identification Pollens}

At the same time daily, the exposed slid was removed from and a new slide was placed on the sampler stand. The exposed slid t was stained with glycerol agar-basic fuchsin stain, covered with a $22 \mathrm{~mm} \times 22 \mathrm{~mm}$ cover slip to dry, sealed and mounted under an optical microscope to carry pollen morphological identification. Refering “Color Atlas of Air-borne Pollens and Plants in China” edited by Bingshan Qiao [9] and according to the prepared pollen standard slides, pollen morphological identification was carried within $22 \mathrm{~mm} \times 22 \mathrm{~mm}$ area to identify the pollen species and count the pollen number. The rare pollens to difficult to identify were photographed by a microscopic camera according to Hong Yaping's pollen Image-taking method [10]. The pollens pictures were sent to prf. Haijuan He, Beijing Union Medical College Hospital, for assistant to identify the pollen species.

\subsection{Collection of Meteorological Data}

The growth and decline of all living beings is influenced by meteorological factors [11] and so is the pollens. The pollens' growth and spread into the atmosphere is closely related to meteorological factors also. After the completion of the investigation, the Taiyuan Downtown's annual meteorological data of abovementioned two years were taken from the Meteorological Bureau of Shanxi Province respectively. Combining with survey data 
the influences of meteorological factors on airborne pollens' growth, decline and spread were comprehensively analyzed, and the relationship between meteorological factors and the spread of pollens were investigated.

\subsection{Comparison of Two Pollen Survey Results}

This survey result was analyzed and compared with the survey result of late 1970s in Taiyuan [6], so was the pollens distribution changes, pollens composition and its influencing factors of annual, spring and autumn and pollen spices collected and spices differences in 30 years.

\subsection{Statistical Analysis Methods}

The pollen species are qualitative data, and were described by the proportion and the detection rate. The atmospheric temperatures and the temperature differences are quantitative data, and were described by the mean data. Line graphs and bar charts were drawn to reflect the counts of pollen grains and the changing trends of average atmospheric temperatures with the month throughout the years.

\section{Results}

\subsection{Annual Survey}

\subsubsection{Annual Survey Results}

365 slides were exposed respectively throughout the year in the 2 airborne pollen surveys. 18,491 (belonging to 24 families and genera) survey and 17,192 (belonging to 35 families and genera) grains of pollens (respectively in 1970s and this surveys) were observed. 12 new families and genera were observed in this survey (according to counts of collected grains respectively: Rumex L., Ginkgo biloba L., Plantaginaceae, Palmae, Cruciferae, Polygonaceae, Albizia Durazz, Urtica L., Luffa L., Ambrosia L., Xanthium L. and Cryptomeria D. Don). The proportion of Populus L. and Salix L. pollens were significantly reduced in the annual and spring airborne pollen constitutes and exited the main Allergenic pollen rank: Populus L. pollen was reduced from $19.37 \%$ [6] and $37.06 \%$ [6] in $1977-1978$ to $12.00 \%$ and $28.79 \%$ in $2008-2009$, and Salix L. pollen from $18.00 \%$ [6], and 34.51\% [6] to $3.16 \%$ and $7.02 \%$, respectively. The annual airborne pollen counts, families and genera, the monthly distribution and the annual total of the two surveys were shown in Tables 1-3.

Table 1. The exposure slide results of the two surveys in 1977-1978 and 2008-2009 in Taiyuan Downtown.

\begin{tabular}{|c|c|c|c|c|c|c|c|c|}
\hline \multirow{2}{*}{ Year } & \multirow{2}{*}{$\begin{array}{l}\text { Exposed } \\
\text { tablets (n) }\end{array}$} & \multirow{2}{*}{ Grains/year } & \multicolumn{2}{|c|}{$\begin{array}{l}\text { The main } \\
\text { allergenic pollens }\end{array}$} & \multicolumn{2}{|c|}{$\begin{array}{c}\text { Absolute } \\
\text { dominant pollens }\end{array}$} & \multirow{2}{*}{$\begin{array}{l}\text { New families } \\
\text { and genera }\end{array}$} & \multirow{2}{*}{$\begin{array}{c}\text { No appearing } \\
\text { families } \\
\text { and genera }\end{array}$} \\
\hline & & & Species & $\% /$ year & Species & $\% /$ year & & \\
\hline $1977-1978$ & 365 & 18,491 & $\begin{array}{l}\text { Artemisia L. } \\
\text { Populus L. } \\
\text { Salix L. } \\
\text { Pinus L. } \\
\text { Chenopodium L. } \\
\text { Amaranthus L. }\end{array}$ & 76.72 & Artemisia $L$. & 26.20 & & \\
\hline 2008-2009 & 365 & 17,192 & $\begin{array}{l}\text { Artemisia L. } \\
\text { Populus L. } \\
\text { Pinus L. } \\
\text { Humulus L. }\end{array}$ & 73.32 & Artemisia $L$. & 38.37 & 12 & 1 \\
\hline
\end{tabular}

Table 2. Month distributions of airborne pollens and annual totals in 1977-1978 and 2008-2009 in Taiyuan Downtown.

\begin{tabular}{|c|c|c|c|c|c|c|c|c|c|c|c|c|c|c|}
\hline \multirow{2}{*}{ Year } & \multirow{2}{*}{$\begin{array}{c}\text { Pollen species, } \\
\text { families and genera }\end{array}$} & \multicolumn{12}{|c|}{ Month number of grains of pollen distribution (grains, \%) } & \multirow{2}{*}{ Total } \\
\hline & & Jan & Feb & Mar & Apr & May & Jun & Jul & Aug & Sep & Oct & Nov & Dec & \\
\hline \multirow[t]{2}{*}{ 1977-1978 } & $24 \%$ & 24 & 15 & 762 & 7183 & 1694 & 318 & 368 & 5922 & 2073 & 56 & 44 & 32 & 18,491 \\
\hline & & 0.13 & 0.08 & 4.12 & 38.85 & 9.16 & 1.72 & 1.99 & 32.03 & 11.21 & 0.30 & 0.24 & 0.17 & 100.00 \\
\hline \multirow[t]{2}{*}{ 2008-2009 } & $35 \%$ & 22 & 56 & 2477 & 1944 & 2755 & 451 & 356 & 3705 & 4811 & 317 & 73 & 225 & 17,192 \\
\hline & & 0.13 & 0.33 & 14.41 & 11.31 & 16.02 & 2.62 & 2.07 & 21.55 & 27.98 & 1.84 & 0.43 & 1.31 & 100.00 \\
\hline
\end{tabular}


Table 3. The contrast of the two investigations of airborne pollens on Populus L. and Salix L. in Taiyuan in 1977-1978 and 2008-2009.

\begin{tabular}{|c|c|c|c|c|c|c|c|c|c|}
\hline \multirow{3}{*}{ Year } & \multirow{3}{*}{ Grains/year } & \multicolumn{4}{|c|}{ Populus L. } & \multicolumn{4}{|c|}{ Salix L. } \\
\hline & & \multicolumn{2}{|c|}{ Grains } & \multicolumn{2}{|c|}{$\%$} & \multicolumn{2}{|c|}{ Grains } & \multicolumn{2}{|c|}{$\%$} \\
\hline & & Year & Spring & Year & Spring & Year & Spring & Year & Spring \\
\hline 1977-1978 & 18,491 & 3583 & 3572 & 19.38 & 37.06 & 3329 & 3326 & 18.00 & 34.51 \\
\hline 2008-2009 & 17,192 & 2062 & 2062 & 11.99 & 28.79 & 543 & 543 & 3.16 & 7.02 \\
\hline
\end{tabular}

\subsubsection{Annual Pollen Spread Peak Distribution and Monthly Mean Temperatures}

In this pollen survey, pollens were visible almost all year around in Taiyuan Downtown. The pollen species and content were in each season were different. There were 2 peaks of pollen spread in spring and autumn every year respectively. The peak in spring was higher than in autumn in 1977-1978 survey, and peak in autumn was higher than in spring in 2008-2009 survey. After the hoar frost descends, plants tended to wither and airborne pollen content in the air reduced to minimum values for the whole year. The monthly airborne pollen counts and spread curves of the two surveys were shown in Table 2 and Figure 1, Figure 2. After the completion of investigation, the Taiyuan Downtown's monthly average temperatures and other meteorological data of above-mentioned two years were taken from the Meteorological Bureau of Shanxi Province respectively. The annual average temperature of this region was $10.23^{\circ} \mathrm{C}$ in $1977-1978$ survey year and $11.72^{\circ} \mathrm{C}$ in $2008-2009$ survey year. The annual average temperature was increased by $1.49^{\circ} \mathrm{C}$ in the past 30 years. The monthly average temperatures and pollen spread curves of the two surveys were shown in Table 4 and Figure 1, Figure 2.

\subsection{Spring and Autumn Surveys}

\subsubsection{Exposure Slides Results of Spring and Autumn}

In 1977-1978 survey year, 22 families and genera were observed in the spring, and 8 in the autumn. In 2008-2009 survey year, in the spring, 30 families and genera were observed, Pterocarya was not collected, harmful species Ambrosia L. was collected, 9 new families and genera to the 1977-1978 survey year were collected, according to counts of collected grains respectively: Ginkgo biloba L., Rumex L., Polygonaceae, Ricinus L., Ambrosia L., Palmae, Cryptomeria D. Don, Helianthus L., Cruciferae; in the autumn, 20 families and genera were observed, Ricinus L., Helianthus L., Fraxinus L. were not collected, harmful species Ambrosia L. was collected, 15 new families and genera to the 1977-1978 survey year were collected, according to counts of collected grains respectively: Rumex L., Plantaginaceae, Broussonetia L., Albizia Durazz, Palmae, Urtica L., Luffa L., Ambrosia L., Polygonaceae, Platanus L., Xanthium L., Cyperaceae, Cupressaceae, Picea Dietr. The pollen contents and constituent ratio in spring and autumn of two surveys (exclusive of unknown pollens) shown in Table 5 and Table 6.

\subsubsection{Pollen Spread Peak Distribution in Spring and Autumn of 2 Survey Years}

The last survey data showed that spring airborne pollen spread peak appeared in April., Populus L., Salix L., Pinus L., Cupressaceae, Ulmus L. and Acer L. ( the collected pollen grains > 100, later the same) are six dominant pollens (accounted for $93.88 \%$ of the spring pollens). This survey data showed that spring airborne pollen spread duration lasted up to three months and three airborne pollen spread peaks appeared, respectively: 1) March peak with Populus L., Ulmus L., Salix L., and Cupressaceae as main species; 2) April peak with Populus L., Salix L., Betula L., Ailanthus Desf, Fraxinus L. and Quercus L. as main species; and 3) May peak with Pinus L., Ailanthus Desf, Picea Dietr and Chenopodium L. \& Amaranthus L. as main species (12 pollens accounted for 95.16\% of spring pollens). Autumn airborne pollen spread of two surveys both appeared in August and September. There were five main pollens: Artemisia L., Humulus L., Chenopodium L. \& Amaranthus L., Gramineae and Ricinus $L$. (accounted for $99.30 \%$ of autumn pollens) in 1977-1978 autumn peak. There were four main pollens: Artemisia L., Humulus L., Chenopodium L. \& Amaranthus L. and Gramineae (accounted for 95.76\% of autumn pollens) in 1977-1978 autumn peak. For airborne pollen spread peak values, spring peak was higher than autumn peak in 1977-1978 survey year; and spring peak was lower than autumn peak in 2009-2009 survey year. Autumn airborne pollen spread appeared dominant in august and clearly weak in September in 1977-1978 survey year; and dominant in August and September and even higher in September in 2008-2009 survey year. The airborne pollen spread peak values of spring and autumn of two survey years is show in Figure 3 and Figure 4. 
Table 4. The average temperatures and temperature difference in 1977-1978 and 2008-2009 survey years in Taiyuan Downtown.

\begin{tabular}{|c|c|c|c|c|c|c|c|c|c|c|c|c|c|}
\hline Annual & Jan & Feb & Mar & Apr & May & Jun & Jul & Aug & Sep & Oct & Nov & Dec & $\begin{array}{l}\text { Annual average } \\
\text { temperature }\left({ }^{\circ} \mathrm{C}\right)\end{array}$ \\
\hline $1977-1978$ & -4.7 & -3.9 & 5.4 & 12.7 & 17.4 & 20.9 & 23.2 & 21.1 & 17.0 & 12.2 & 3.0 & -1.6 & 10.23 \\
\hline 2008-2009 & -5.1 & 1.5 & 6.7 & 14.9 & 19.2 & 24.5 & 24.9 & 23.5 & 17.8 & 11.5 & 3.9 & -2.7 & 11.72 \\
\hline $\begin{array}{l}\text { Temperature } \\
\text { difference }\end{array}$ & -1.4 & 5.4 & 1.3 & 2.2 & 1.8 & 3.6 & 1.7 & 2.4 & 0.8 & -0.7 & 0.9 & -1.1 & 1.49 \\
\hline
\end{tabular}

Table 5. Pollen contents and constituent ratio in spring and autumn in 1977-1978 and in 2008-2009 in Taiyuan Downtown.

\begin{tabular}{|c|c|c|c|c|c|c|c|c|c|c|c|c|c|c|}
\hline \multirow[b]{3}{*}{ Month } & \multicolumn{7}{|c|}{ 1977-1978 } & \multicolumn{7}{|c|}{ 2008-2009 } \\
\hline & \multicolumn{4}{|c|}{ Spring } & \multicolumn{3}{|c|}{ Autumn } & \multicolumn{4}{|c|}{ Spring } & \multicolumn{3}{|c|}{ Autumn } \\
\hline & Mar & Apr & May & Total & Aug & Sep & Total & Mar & Apr & May & Total & Aug & Sep & Total \\
\hline Grains & 762 & 7183 & 1694 & 9639 & 5922 & 2073 & 7995 & 2471 & 1939 & 2753 & 7163 & 3676 & 4782 & 8458 \\
\hline$\%$ & 7.91 & 74.52 & 17.57 & 100.00 & 74.07 & 25.93 & 100.00 & 34.50 & 27.07 & 38.43 & 100.00 & 43.46 & 56.54 & 100.00 \\
\hline
\end{tabular}

Table 6. Pollen contents, constituent ratio and families and genera in spring and autumn in 1977-1978 and in 2008-2009 in Taiyuan Downtown.

\begin{tabular}{|c|c|c|c|c|c|c|}
\hline \multirow{2}{*}{ Year } & \multirow{2}{*}{ Season } & \multicolumn{2}{|c|}{ Pollens } & \multirow{2}{*}{$\begin{array}{c}\text { Families and } \\
\text { genera }\end{array}$} & \multirow{2}{*}{$\begin{array}{c}\text { New families and } \\
\text { genera }\end{array}$} & \multirow{2}{*}{$\begin{array}{c}\text { No appearing } \\
\text { families and genera }\end{array}$} \\
\hline & & Grains & $\%$ & & & \\
\hline \multirow[t]{3}{*}{ 1977-1978 } & Spring & 9639 & 52.13 & 22 & & \\
\hline & Autumn & 7995 & 41.67 & 8 & & \\
\hline & Total & 18,491 & 100 & 30 & & \\
\hline \multirow[t]{3}{*}{ 2008-2009 } & Spring & 7163 & 41.62 & 30 & 9 & 1 \\
\hline & Autumn & 8458 & 49.20 & 20 & 15 & 3 \\
\hline & Total & 17,192 & 100 & 50 & 24 & 4 \\
\hline
\end{tabular}

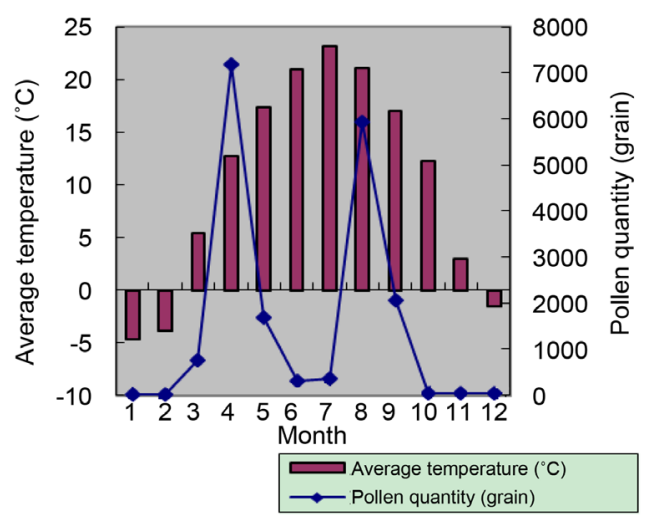

Figure 1. Average temperature and air pollen distribution in Taiyuan in 1977-1978.

The highest monthly average temperature was July $\left(23.2^{\circ} \mathrm{C}\right)$ and formed the peak top of monthly average temperature distribution curve in 1977-1978 survey year. The higher monthly average temperatures were June, July and August $\left(24.5^{\circ} \mathrm{C}, 24.9^{\circ} \mathrm{C}\right.$ and $23.5^{\circ} \mathrm{C}$ respectively, mean $\left.24.3^{\circ} \mathrm{C}\right)$ and formed nearly a plateau duration last up to three months of monthly average temperature distribution curve in 2008-2009 survey year. The monthly average temperatures, average temperature distribution curves and relationship between the monthly average temperatures and the airborne pollen spread peak were shown in Table 3 and Figure 3 and Figure 4. 


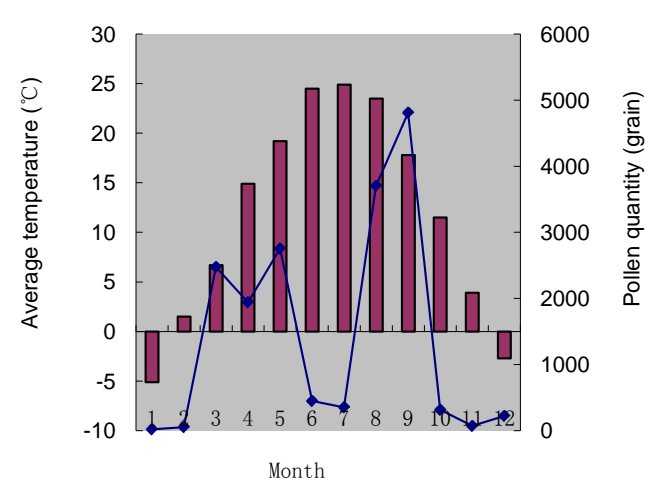

Average temperature $\left({ }^{\circ} \mathrm{C}\right)$

$\rightarrow$ Pollen quantity (grain)

Figure 2. Average temperature and air pollen distribution in Taiyuan in 2008-2009.

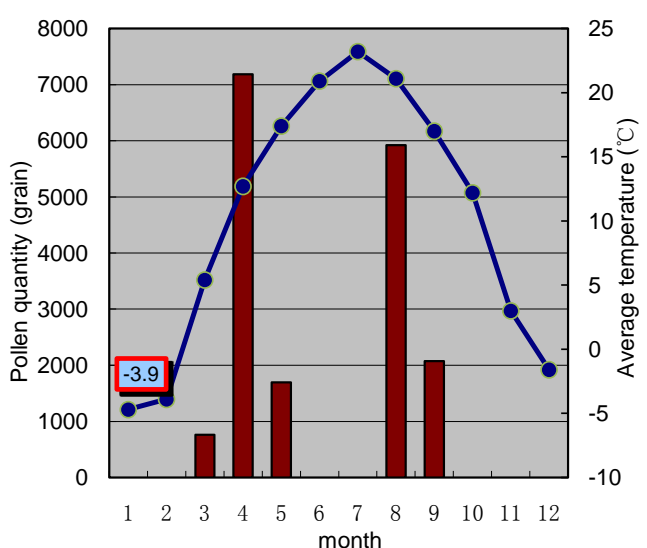

$\square$ Pollen quantity (grain)

-๑-Average temperature $\left({ }^{\circ} \mathrm{C}\right)$

Figure 3. Airborne pollens of spring and autumn and monthly average temperature distributions in 19771978 in Taiyuan Downtown.

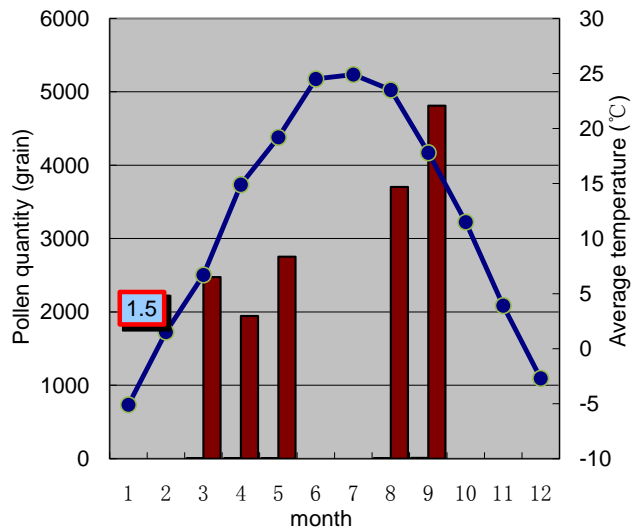

$\square$ Pollen quantity (grain)

- - Average temperature $\left({ }^{\circ} \mathrm{C}\right)$

Figure 4. Airborne pollens of spring and autumn and monthly average temperature distributions in 2008-2009 in Taiyuan Downtown. 


\section{Discussion}

\subsection{The Relationships between Airborne Pollen Spread Duration with Climate in Two Surveys}

Taiyuan City is located in the middle of the Yellow River basin of north China; has a temperate monsoon climate, have clear four seasons throughout the year, is no severe cold in winter and intense heat in summer, has an annual average temperature above $10^{\circ} \mathrm{C}$; has a large plant species, a longer flowering duration and longer plant growing season. In the two surveys, the same location, the same fixed-point pollen sampling method were selected. The survey results showed that the airborne pollen spread were throughout the year and both formed two spread peaks in spring and autumn. Spring airborne pollen spread peaks duration: in 1977-1978 survey year, the spread peak appeared in April, lasted about one month, consist of Populus L., Salix L., Pinus L., Cupressaceae, Ulmus L. and Acer L.; in 2008-2009 survey year, the spread peaks appeared in march, April and May, lasted long for three months, formed "M" three peaks, respectively: 1) March peak with Populus L., Ulmus L., Salix L., and Cupressaceae as main species; 2) April peak with Populus L., Salix L., Betula L., Ailanthus Desf, Fraxinus L. and Quercus L. as main species; and 3) May peak with Pinus L., Ailanthus Desf, Picea Dietr and Chenopodium L. \& Amaranthus L. as main species. Autumn air spread pollen spread peaks duration: in two surveys the spread peak both appeared in August and September; in 1977-1978 survey year, the autumn peak appeared higher in August and Significantly weak in September; in 2008-2009 survey year, autumn peak appeared high in August and Significantly higher in September; in two surveys the spread peak both consist of Artemisia L., Humulus L. and Chenopodium L. \& Amaranthus L. The air temperature gradually rose in March in 1977-1978 survey year and began to rise in February in 2008-2009 survey year. The air temperature gradually declined in October both in two survey years. The annual average temperature was $1.49^{\circ} \mathrm{C}$ higher in $2008-2009$ survey year than 30 years ago. The average temperature in February was $5.4^{\circ} \mathrm{C}$ higher in $2008-2009$ survey year than 30 years ago. The average temperatures in spring and autumn were higher in 2008-2009 survey year than the same duration 30 years ago, suggesting that warmer climate might be the main reason that the spring airborne pollen spread was peaked earlier and lasted long for up to 3 months, and autumn airborne pollen spread maintained strong for up to 2 months and was peaked later to September.

\subsection{The Relationships between Airborne Pollen Families and Genera with Vegetation in Two Surveys}

Nearly 30 years in Taiyuan Downtown, as the process of modernization, industrialization and urbanization, the green area of expanded, new plants were introduced, old plants were eradicated, the species of flowers, grasses and trees increased, airborne pollen contents increased, the annual collected airborne pollen species increased from 24 to 35, spring airborne pollen species increased from 22 to 30, and autumn airborne pollen species increased from 8 to 20. The dominant pollens were also varied in the 30 years. Before 1980s, willow catkins and poplar blowballs fluttered all over the sky in spring in Taiyuan Downtown. A large number of willows and poplars had been replaced by Sophora japonica, ginkgo, etc. The proportion of Populus L. and Salix L. pollens were significantly reduced in the annual and spring airborne pollen constitutes. This might be the main reason that the spring airborne pollen spread peak was exceeded by the autumn peak and the spring airborne pollen peak predominantly Populus L. and Salix L. pollens reason was significantly lower in 1977-1978 than 30 years ago. In 2008-2009 survey, the spring airborne pollen spread duration lasted for up to three months, the main pollens collected $>100$ grains were constituted by 6 species (Populus L., Salix L., Pinus L., Cupressaceae, Ulmus L. and Acer L., respectively) in 1977-1978 and by 12 species (Pinus L., Populus L., Ailanthus Desf, Salix L., Ulmus L., Betula L., Cupressaceae, Quercus L., Fraxinus L., Artemisia L., Chenopodium L. \& Amaranthus L. and Picea Dietr, respectively) in 2008-2009; the autumn airborne pollen spread duration lasted for up to two months, the main pollens collected $>100$ grains were constituted by 5 species (Artemisia L., Humulus L., Chenopodium L. \& Amaranthus L., Gramineae, and Ricinus L., respectively) in 1977-1978 and by 4 species (Artemisia L., Humulus L., Chenopodium L. \& Amaranthus L. and Gramineae, respectively) in 2008-2009. The collected pollens were 12 species more than the last survey and Ricinus $L$. which was collected with a higher content in 1977-1978 survey was not detected in 2008-2009 survey. The above changes suggest that plants viriation would certainly change content of certain airborne pollens and strengthening virescence could change the constitute of airborne pollens. 


\section{Conclusion}

Comparative analysis of spring and autumn data in two airborne pollen surveys in Taiyuan downtown is summarized as follows: 1) The spring airborne pollen species was increased from 22 in 1977-1978 to 30 in 2008-2009, and the autumn airborne pollen species was increased from 8 in 1977-1978 to 20 in 2008-2009. 2) The absolute dominant spring airborne pollens were Populus L. (37.06\%) and Salix L. (34.51\%) in 1977-1978, and Pinus L. (29.53\%) and Populus L. (28.79\%) in 2008-2009. The absolute dominant autumn airborne pollens in last and this surveys were both Artemisia L. (59.05\% and 70.21\%, respectively), and Humulus L. became the main autumn allergenic pollen. 3) Airborne pollen spread peak was higher in spring than in autumn in 19771978 survey, and in autumn than in spring in 2008-2009 survey. 4) Warmer climate might be the main reason that the spring airborne pollen spread was peaked earlier and lasted long for up to 3 months, and autumn airborne pollen spread maintained strong for up to 2 months and was peaked later to September. 5) Plants variation led to the fact that the annual percentage contents of Populus L. and Salix L. were significantly lower than 30 years ago, and the pollen spread peaks between spring and autumn were reversed; strengthening virescence could change the constitute of airborne pollens. 6) It is reported in 1977-1978 survey that exotic invasive harmful plant ragweed in North China was spread in inland city Taiyuan [4]. The hospitalized clinical allergen testing records of recent 20 years [12] were summarized and analyzed, and patients allergic to ragweed were found in the 1990s. The detection rate of ragweed pollen in hospitalized allergy patients was only 6.36\% (28/440) in January 1994-December 1995 [12], and up to 31.24\% (448/1434) 10 years later, in January 2004-December 2005 [12]. Allergists could not ignore the exotic invasive harmful allergenic pollen ragweed.

\section{References}

[1] Ye, S.T. (1998) Allergology. Science Press, Beijing, 198-206.

[2] He, G.W. (2005) The Mechanism Revealed on Traditional Chinese Medicine to Treat Hay Fever and Adjust Atopic Constitution. China News of Traditional Chinese Medicine.

[3] Han, D.M., Zhang, L., Huang, D., et al. (2007) Self-Reported Prevalence of Allergic Rhinitis in Eleven Cities in China. Chinese Journal of Otorhinolaryngology Head and Neck Surgery, 42, 378-384.

[4] Li, W.-K. and Wang, C.-S. (1986) Survey of Air-Borne Allergy Pollens in North China: Contamination with Ragweed. Allergy and Asthma Proceedings, 7, 134-143. http://dx.doi.org/10.2500/108854186779047771

[5] Allergy Group of Otolaryngology Department of the First Hospital of Shanxi Medical College (1983) Airborne Allergenic Pollen Distribution Investigation. Shanxi Medicine Journal, 12, 272-273.

[6] The Leading Group of China Airborne Allergenic Pollen Survey (1991) Airborne Allergenic Pollen Survey in China. Beijing Publishing House, Beijing, 40-42.

[7] Qiao, B.S. (2002) Allergology Experiment Technique. 2nd Edition, China Union Medical University Press, Beijing, 176-182.

[8] He, H.J., Wang, L.L. and Zhang, H.Y. (2008) Analysis of Airborne Pollens in Beijing Urban Area. Chinese Journal of Allergy \& Clinical Immunology, 2, 179-183.

[9] Qiao, B.S. (2005) Color Atlas of Airborne Pollens and Plants in China. Peking Union Medical University Press, Beijing, 1-298.

[10] Hong, Y.P. (2007) A Simple Method of Preparing Thin of Fresh Pollen under Microscope. Bulletin of Biology, 42, 56-57.

[11] Xie, H.X., Ma, L.L., Liu, Z.G., et al. (2006) Correlation between Airborne Pollen Dispersal and Seven Weather Factors. Chinese Journal of Clinical Rehabilitation, 10, 56-58.

[12] Cai, H.J., Zhang, K.J., Wang, C.H., et al. (2008) Allergen Skin Test in the Diagnosis of Patients with Allergic Disease Value Research. Journal of Chinese Basic Medicine, 15, 1601-1602. 